\title{
Designing Ethnographic Encounters for Enriched HCI
}

\author{
Jo-Anne Bichard, Catherine Greene, Gail Ramster, and Tom Staples \\ Helen Hamlyn Centre for Design, Royal College of Art, London, UK \\ Jo-anne.bicharderca.ac.uk, \\ \{catherine.greene, Gail.ramster, tom.staples\}@network.rca.ac.uk
}

\begin{abstract}
This paper present three case studies of design research in HCI that has utilized an ethnographic approach to understand user needs. All of the projects were undertaken at the Helen Hamlyn Centre for Design (HHCD), based at the Royal College of Art. The HHCD specialises in an inclusive design philosophy, which seeks to directly involve users in the design process. Two of the projects were undertaken as Research Council United Kingdom (RCUK) funded initiatives, and one was commissioned by a major technology company. They highlight how a design ethnography approach can be both rigorous for academic design research within HCI, and dynamic for the needs of the commercial sector.
\end{abstract}

Keywords: ethnography, inclusive design, design research methods, user engagement.

\section{$1 \quad$ Introduction}

The philosophy of inclusive design focuses on the direct engagement with people as the end users of design. In particular, engagement has been sought with 'expert users' [1], whose first hand experience of ageing, impairment and/or their immediate community can highlight the challenges people face in their encounters with poorly designed products, environments and/or services. Working with users whilst engaging a range of ethnographic methods can provide a deeper level of data for designers to explore and innovate from.

Millen [2] has noted that the incorporation of ethnographic methods has become increasingly popular within the practice of human-computer interaction. Yet, Millen also indicates that 'there has been a common misunderstanding among HCI professionals about the analytical nature of ethnographic research' [2]. This paper aims to address this concern by introducing three case studies of ethnographic design research that explores HCI, and highlights how the ethnographic method provided indepth data for the design researchers to analyse as well as a robust engagement methodology for the participants in the inclusive design research process.

\section{Ethnography}

Ethnography is a qualitative research process that principally involves fieldwork amongst a chosen group of people. Undertaking an ethnographic study is the key 
method within the discipline of social and cultural anthropology [3], and its level of detail and in-depth analysis has resulted in the practice receiving wide consideration within design research, with many design consultancies and research groups actively including anthropologists within research teams [4].

Traditional ethnographic encounters often take place over many months (in the case of Social Anthropology $\mathrm{PhD}$ research up to a year), and analysis can take equally as long. It is therefore a time intensive method that has required a considerable amount of editing to be suitable for both the time demands of the commercial design sector and the swift design responses in artifact development. Hence a 'rapid ethnography' [2] has been developed in which short focused field studies are undertaken to gain a wider understanding of the context of use for the intended design output. Under a rapid ethnographic method, participant observation, in which researchers directly interact with informants, may take place over a few days instead of many months. Open-ended interviews are condensed into a focused interview that directly explores the issue at hand. Such rapid response requires a certain focus in preliminary research before the ethnographic process begins. For example the key activities should be identified so that research questions can be focused directly on addressing these. Key informants should be identified and recruited to the project and interactive techniques should be developed to draw out specific user behavior [2].

Millen uses photographic analogies to define the difference between traditional and rapid ethnographic methods. The traditional method is considered 'a very wide angle research lens' in which the breadth of data collected may not present initial insights for a time poor design team. In contrast, a rapid ethnographic approach is viewed as a telephoto lens in which the research team identify the key question to be addressed and knows where to aim the lens [2].

Wasson notes that ethnography has been associated more with data collection then analysis, and that consideration should be given to the level of knowledge that anthropological training brings to the analysis of the resulting data. This includes the interpretation of ethnographic material based on deeper cultural understandings, a narrative that focuses on the world of user-product/ environment/ service interactions, and insight on how the focus of the study may be incorporated into daily activities, and carry symbolic meanings. Without a deeper understanding gained in data analysis, ethnographic studies especially undertaken under the rapid methodology, can run the risk of becoming 'a pale shadow of itself', and therefore should not be considered as such if merely undertaken by a 'designer with a camera' [4].

This paper will present three case studies that have employed ethnographic techniques within their design research methodology. The studies highlight how the use of ethnography (both rapid and more in-depth) has provided rich qualitative data which has not only informed greater understanding of people's interactions with environments, products and services, but also produced innovative design solutions, especially with regards to people's encounters with technology. 


\section{The Great British Public Toilet Map (Jo-Anne Bichard, Gail Ramster and Catherine Greene)}

The Great British Public Toilet Map was developed as the key deliverable for the TACT3 (Tackling Ageing Continence through Theory Tools \& Technology) research project. TACT3 was a multidisciplinary collaboration that ran between 2008-2011, between Brunel University, the Universities of Sheffield, the West of England and Manchester, the Dalarna Research Institute and the Bristol Urological Institute and the Royal College of Art. TACT3 was funded by the New Dynamics of Ageing (NDA) Research programme http://www.newdynamics.group.shef.ac.uk/ 'a seven year multidisciplinary research initiative with the ultimate aim of improving quality of life for older people'. The NDA, which was funded by all of the UK's research councils, has been considered 'the most ambitious research programme on ageing ever mounted in the UK'.

Working under the title 'Challenging Environmental Barriers to Continence' the researchers undertook a series of interviews with two key stakeholder groups, namely members of the public as users of publicly accessible toilets and members of professional bodies involved with the service delivery of publicly accessible toilets. This second group included architects who specialise in the siting, design and planning of provision, managers of provision from local authorities, department stores and transport terminals, and community groups interested in promoting local provision. In total 101 interviews were conducted with users (covering the age ranges of the needs of a new born child to Nonagenarian's), in which their experiences of toilet use and provision were explored. Previous research has noted that in the design and management of public toilet provision there is often conflict between what users require for toileting in comfort and dignity, and what providers can manage. This has often resulted in design decisions that take on an 'access versus fortress' [5] agenda in which designing out elements of anti-social behaviour take precedence in the design brief to the detriment of wider user inclusion and access.

\subsection{Rapid Ethnography through Participatory Design Games}

Whilst the interview process yielded strong data on preferences and avoidances, deeper engagement was required. Given the highly personal nature of the research subject, a traditional ethnographic approach such as participant observation could not be incorporated. To overcome this issue, the design researchers developed participatory design game that was able to explore this sensitive area in more depth. The game involved participants working together using a set of picture associated cards to design their ideal public toilet. By matching normally diametric opposite needs together such as that of an older man and younger woman (figure 1), or an able bodied man with a women who uses a wheelchair, the game provided participants with tools to work together and identify shared needs. The data gathered from the 'game' method revealed that all the participants agreed on the need for facilities to be clean, and for the design of items such as locks and hand dryers to be easy to understand and effective. The game also highlighted the need for publicly accessible toilets to meet individual user needs, and that these are varied and complex. Better 
information about provision would improve the service for users, giving them the ability to find a toilet that meets their personal needs.

Here the researchers found a direct correlation with the data gathered through focused interviews with providers, in which the management of information on service provision emerged as a problematic area that needed to be addressed.

Based on the issue of information management raised by both user groups, the research refocused from critiquing physical space to exploring the opportunities of digital space to deliver a framework for improved service delivery. Initially, and based on their inclusive philosophical perspective, the researchers explored crowd sourcing as a method of data capture on current toilet provision. However an analysis of crowd-sourced data highlighted how crowd-sourced information alone is insufficient as it can be inaccurate and become quickly obsolete [6].

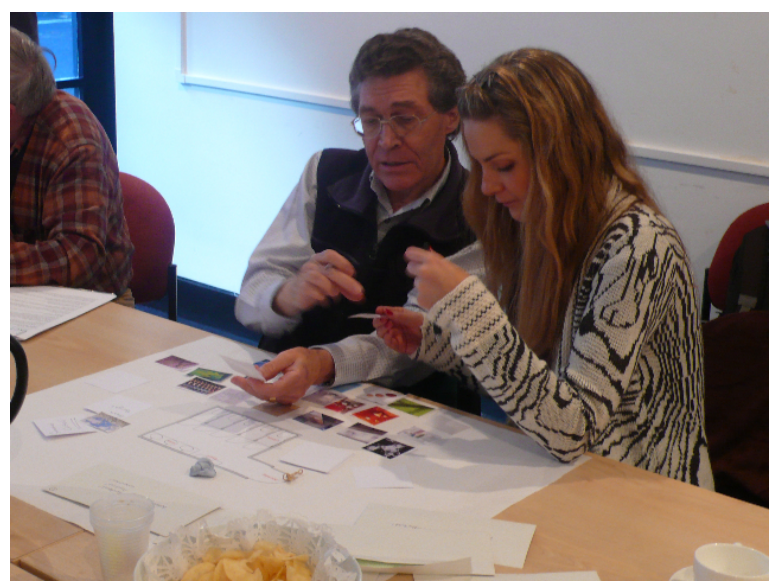

Fig. 1. Participatory Design Game for Publicly Accessible Toilets

\subsection{Digital Research Tools, Digital Data and Digital Resource}

Reframing the research into digital space also expanded the inclusive community engagement to include those with interests in the UK's open data movement. Community members were contacted and communicated with using Twitter and the development by Ramster of the blog 'Public Toilets and...' http://gailknight.wordpress.com/. These resources were actively used as data gathering tools as well as to feedback findings and question data collection barriers encountered during the research process [7].

Currently, there is no centrally collated information, database or inventory of UK publicly accessible toilets. Coupled with the UK government's call for more open data to be released especially in relation to public services, the research focused on delivering a resource that explored how open data is gathered and then used.

The development of The Great British Public Toilet Map http://greatbritishpublictoiletmap.rca.ac.uk/ aimed to do this through its public participation features in which it not only retrieves released open data on public toilet provision but also provides a platform for members of the public to request that such data is made available to populate the map. 


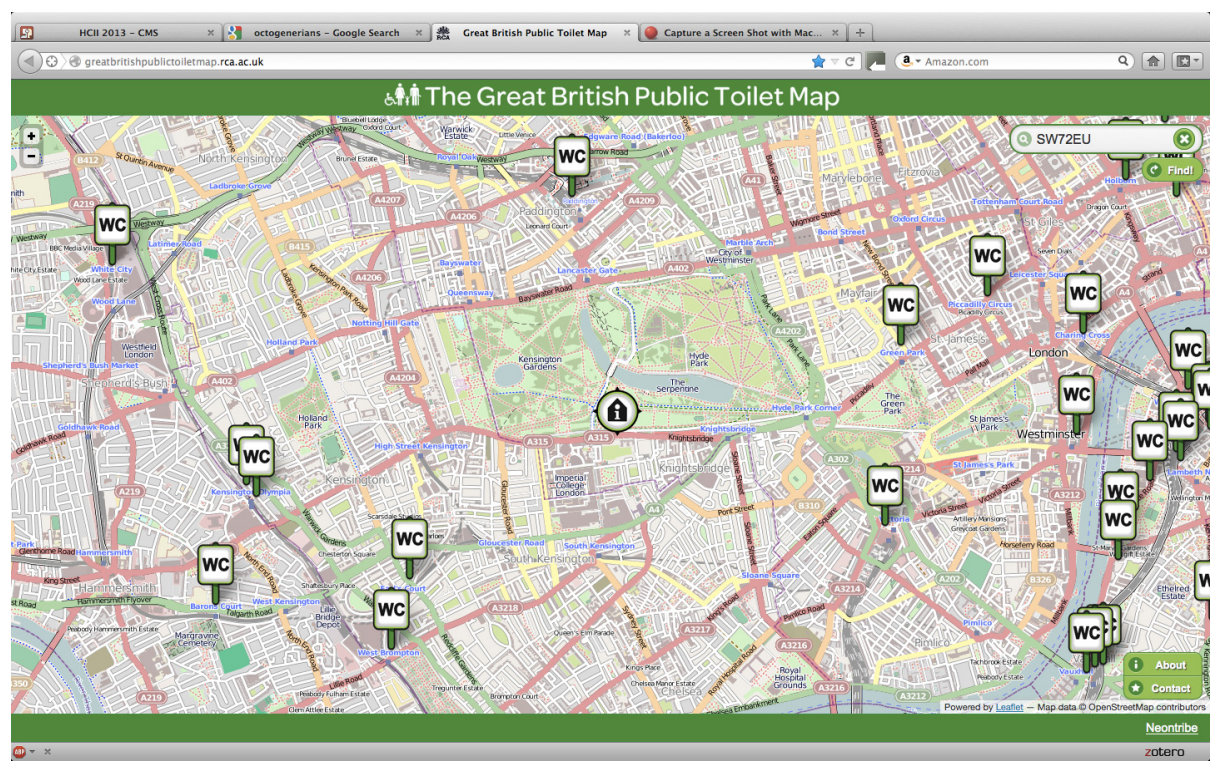

Fig. 2. The Great British Public Toilet Map

\section{Mobile Working Lives (Tom Staples and Catherine Greene)}

The current selection of information technologies (IT's) such as laptops, smartphones and tablets provide a degree of greater flexibility and mobility to working life, especially those whose work can be considered traditionally 'mobile' such as plumbers, salesmen, paramedics and builders. For example - whereas once a plumber would have a series of locations to visit including visiting the client and ordering required parts. Much of this can be done remotely whilst 'on the job'.

Mobile Working Lives was a pan European project in partnership with Samsung Design Europe. It incorporated focused ethnographic interviews with mobile workers in four countries, and four languages. The diversity of language in this project required the researchers to develop a specific tool for the ethnographic encounter that could transcend language barriers. This tool comprised a mapping exercise to act as a conversational prompt during ethnographic interviews. Interviews were conducted after a morning of shadowing the mobile worker, an echo of the traditional participant observation method.

A total of 32 people participated in the study, their ages ranged form 21-62 and they represented 29 different professions. The variety of professions revealed surprising uses of new social technologies for example, a TV Crew in Oslo used Facebook for workplace banter as silence was often required in their workplace, the TV set. In London, a roof thatcher whilst appreciating how smartphones had helped him manage his business felt that he should keep it hidden when meeting clients as such technology did not fit with wider social models of a craftsman. The thatcher felt that being seen with his smartphone may damage a sense of trust held by clients towards him. 


\subsection{Rapid Ethnography through Interactive Activity Mapping}

The mapping process began by asking the participant to think of a recent busy day, to recall where they went (for work or non-work reasons). Each location was written on a specific sticker and placed on a sheet of paper with a line drawn between the places indicating the journeys and the order in which they were made (figure 3 ).

The participant was then asked what professional and social activities took place at each location. Each activity was then written on a specific sticker and attached to the location where it took place (figure 4).

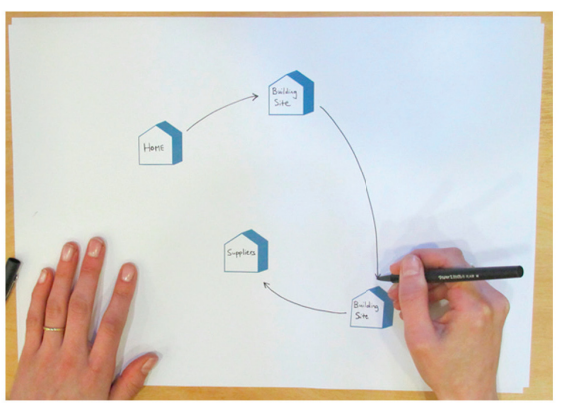

Fig. 3. Journey map

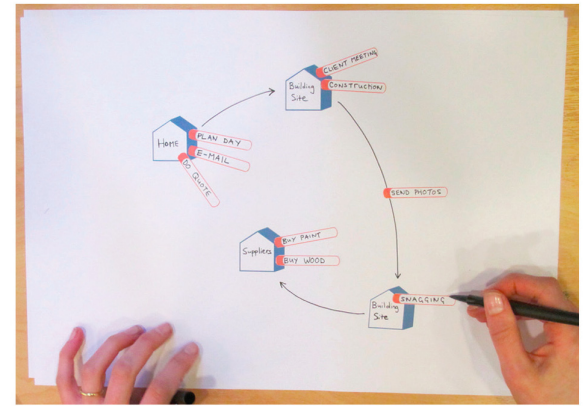

Fig. 4. Activities map

At this stage a sheet of tracing paper was laid on top of the locations and activities sheet and used to capture a new layer of data focused on the interactions the participant had that day. Specific stickers were then used to map where these interactions took place, with whom and the nature (face to face, mobile phone call, SMS, VOIP call or email) of the interaction (figure 5).

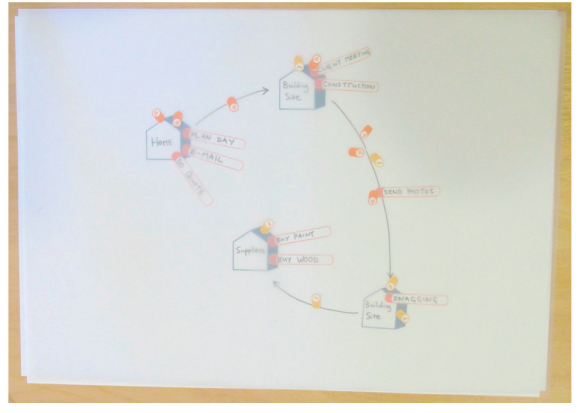

Fig. 5. Interactions map

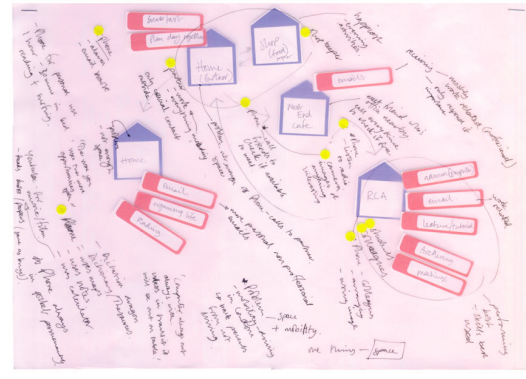

Fig. 6. Integration map

Once all the factors of the day were mapped out, it was then possible to ask questions like: 'Where did you feel your skills were best used in the day', and also, 'where were you happiest', 'what problems did you have in the day', and how did you solve those problems'? This final stage was also used to prompt subjects such as how much the participant values what they do, who their support networks are, and how 
self-reliant they are. By mapping the answers this way it was possible to see patterns of working, areas of high and low activity and which skills are used where. It was also possible to see the areas of work and non-work activities, where they overlapped and what the role of technology was in each of these activities (figure 6).

\subsection{Findings}

The research delivered five key findings that described mobile workers interaction with information technologies. These were:

- Work/life. There now exists the potential to work near constantly, with mobile devices giving access to contacts and working tools anywhere. While this is liberating to many people it can also make managing ones time more difficult.

- Transitions. Being able to adapt and be flexible in how you work is key to mobile working. Journey times serve as a break between jobs giving people time to adapt or 'change clothes' between one task and the next.

- Learning. Mobile technologies are providing mobile workers with new routes to information. While opening up new processes for learning and sharing information, these technologies also pose a barrier to others who struggle to keep up with them and the increasing demands they bring.

- Channels. Mobile workers receive information in lots of different formats, printed, as a PDF on a phone, or as an excel file on a computer. The problem is that while a person receives something in one format it may be more useful to them in another format and they end up processing it into a different format so that they can use it in the way they want. In the process information is often lost or miscommunicated.

- Networks. More likely to work on their own and therefore lack the support of a close work community, mobile workers often rely on their own personal networks to act as this support. Therefore having a wide personal network can be really beneficial and is important but maintaining these contacts takes time.

\section{Creative Citizens (Gail Ramster and Catherine Greene)}

The Creative Citizen project is a three-year study (May 2012-October 2014) funded by the Arts and Humanities Research Council (AHRC) and Engineering and Physical Sciences Research Council (EPSRC) Connected Communities and Digital Economy Programme. The multi-disciplinary research is in collaboration between Cardiff University, University of Birmingham, Birmingham City University, the Open University, the University of the West of England and The Royal College of Art. The RCA and the Open University are leading on a strand of the research called 'Community Led Design' that is exploring how social media and web tools could offer new opportunities for communities to come together to redesign spaces and/or services within their neighbourhoods.

\subsection{Introducing Rapid Ethnography Techniques to Students}

The researchers are working directly with community groups to understand the medias they have employed to engage wider members of the community and if new 
technologies may help. Currently there is very little research to show how such technologies are used. As part of the project the researchers designed a crossdisciplinary student engagement event with twenty students at the Royal College of Art. This event aimed to introduce student designers to rapid ethnographic techniques for community design focused research. Divided into Four teams, the students worked with three London based community projects. Each community group set a challenge for the students to respond to in order to kick-start ideas for their specific project.

\subsection{The Community Projects}

Streets Ahead is a neighbourhood group in the London Borough of Stockwell. Their objective is the greening of their local urban spaces to create safe places for children to play and neighbours to meet. Their project 'Grass Routes' has led to a local street, once a space for parking cars, being transformed into a shared space with flower beds, trees and children's play equipment. The challenge for the students was to look at how residents could connect their local stories past, present and future to the physical spaces of the local area.

Tate South Lambeth library is a small, local library in Vauxhall South West London, and situated in a beautiful Victorian building. Once threatened with closure, it now offers film nights, language classes, gardening groups, and other events, as well as having a traditional library service. The challenge for the students was to look at how the library could attract, and be attractive to, more local people.

The Mill, was once a local library, but was closed by the local authority in 2007. Local residents gained access in 2011 and begin to transform the venue into a neighbourhood centre. With NGO support it is now home to a poetry group, knitting club, film society, social innovation start-ups, community breakfasts, and a mentoring service amongst others. It has managed to reach most groups in the area except the age group 16 to 24 year olds. Due to the London riots in 2011 the Mill is very conscious that this very important group must be included within their neighbourhood services. The challenge to students was 'What new services, spaces, events could attract teenagers?'

\subsection{Rapid Ethnography as Multi-disciplinary Technique}

With only three days to respond to them. The multi-disciplinary teams, comprising RCA students from visual communications, service design, innovation design engineering, animation, design products, information experience design, design interactions, photography and history of design, spent time with local residents and community participants as well as those hard to reach groups identified by both the library and the Mill. Data gathering methods included focused interviews and participant observation. Based on these ethnographic encounters they developed ideas in direct co-operation with users and received immediate feedback from the community. In one case a team prototyped their idea on day 2 by running a games event with young people at the Mill. These experiences and ideas were then presented on the third day to both the communities and RCA staff and students for open discussion and feedback. 

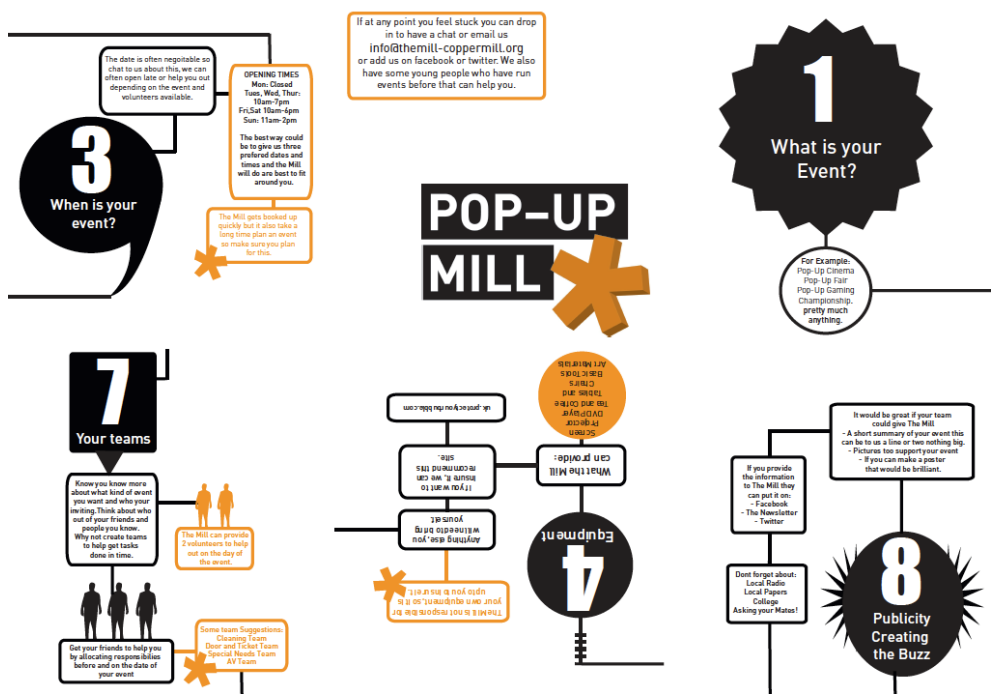

Fig. 7. Process chart for community pop-up event

\subsection{Rapid Ethnographic Reflections}

At the start of the three days the students had been asked to consider the role of technology in meeting their challenge, whether this was communication technologies or more interactive digital interventions. Initially for the students a technology based intervention seemed almost 'obvious'. However, during the final presentations it was interesting to see that after the ethnographic encounter, (being on-site, listening to those involved and understanding the needs of the respective projects), each team chose to respond with proposals that relied predominantly on small media and face-to-face

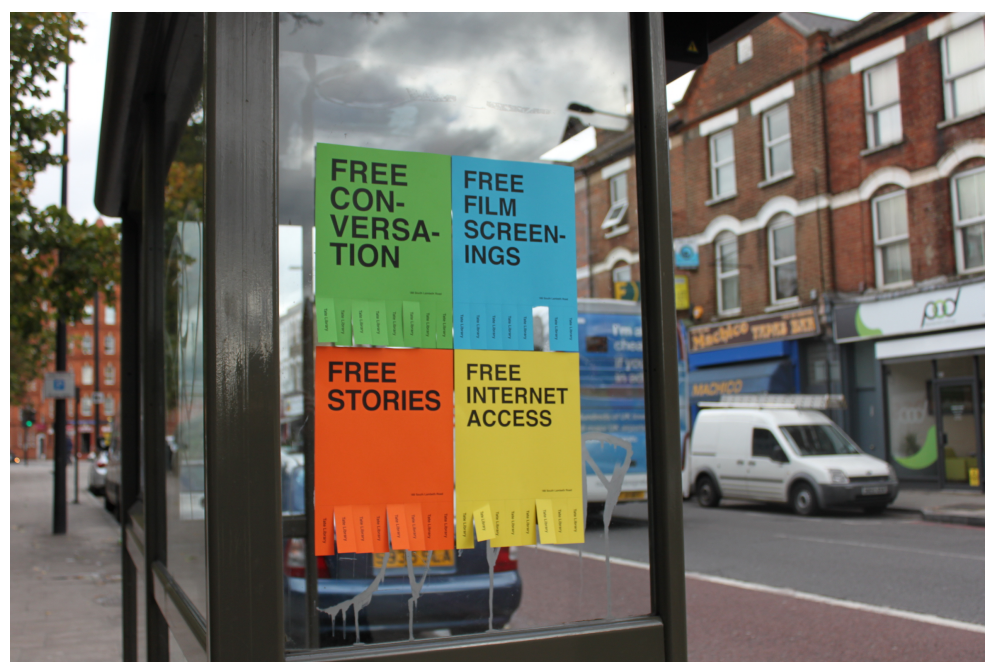

Fig. 8. Small media initiatives 
initiatives, this included; noticeboards, flyers, events, that were only supplemented by a simple online presence. Collectively the teams identified the need for media(s) to be universally accessible (not necessarily HCI based), hyperlocal, cheaply reproducible, and reliant on resources readily available such, as an A4 colour printer.

\section{Conclusions}

This paper has presented case studies of design research that has incorporated a technology (HCI) perspective. The case studies focus on an inclusive design philosophy in which users as experts in their own lives participate in the design process. Rapid ethnography offers a methodology to facilitate this inclusion, but may also require input from designers to address certain needs such as sensitivity of a subject as in the case of toileting or crossing language barriers as in the case of mobile working lives. Traditional ethnographic techniques might have afforded time for deeper interviews and sensitive environmental observations (toileting), or for researchers learning language skills (or even being employed with such skills), yet in the mobile working lives project, the researchers were designers employed for design skills not linguistic ability, hence an innovative mapping tool was developed that could be used across cultures of language and profession. Similarly, a participative design game was constructed for users to talk across social groups about highly personal and intimate concerns with regards to toileting.

Engaging students in rapid ethnographic techniques provided them a tentative insight into reflexivity, a valued aspect of ethnographic encounter for the ethnographer themselves. Aull-Davis suggests that a reflexive approach incorporates an attention to multiple perspectives in which peoples separate social realities become valid objects of knowledge and therefore valid and valuable research fields [3].

\section{References}

1. Coleman, R.: The Case for Inclusive Design - an overview. In: Proceedings of the 12th Triennial Congress, International Ergonomics Association and the Human Factors Association of Canada (1994)

2. Millen, D.R.: Rapid Ethnography: Time Deepening Strategies for HCI Field Research. In: Dis 2000, pp. 280-286 (2000)

3. Aull-Davis, C.: Reflexive Ethnography: A guide to researching selves and others. Routledge, London (1999)

4. Wasson, C.: Ethnography in the Field of Design. Human Organization 59(4), 377-388 (2000)

5. Greed, C.: Inclusive Urban Design: Public Toilets. Architectural Press, Elsevier, Oxford (2003)

6. Knight, G., Bichard, J.: Publicly Accessible Toilets: An inclusive design guide. Helen Hamlyn Centre for Design. Royal College of Art, London (2011)

7. Bichard, J., Ramster, G.: Improving public services through open data: The Great British Public Toilet Map. Municipal Engineer Proceedings of the Institute of Civil Engineers 165(ME3), 157-165 (2012) 